\title{
Final Comment
}

\section{Clocks to Computers: Some Clarifications}

\author{
Frans van Lunteren
}

\begin{abstract}
This final comment aims to dispel legitimate concerns expressed in some of the commentaries about the nature of the successive epistemic regimes inherent in the "big picture" offered in "Clocks to Computers" and the use of machines as emblems for these regimes. It also addresses the place in the proposed scheme of some key figures in the history of science that do not obviously fit these regimes.
\end{abstract}

T $t$ is a rare and gratifying privilege to have one's historiographical musings subjected to the scrutiny of such a distinguished and authoritative panel. The incisive comments and suggestions of the commentators are extremely welcome-all the more so as my reflections represent only the initial stage of what I hope to turn into a larger project. It is, therefore, with a sincere sense of gratitude to the Editor of Isis and to my learned critics that I take up some of the points raised by the commentators. In doing so, I want to focus on the different roles of machines in my scheme, their scope for characterizing a complex set of developments during an extensive period, and the nature of the epistemic realms or knowledge regimes (for want of a better word) related to these machines.

Few of the commentators argue with the weak claim that in the past machines played an important role as resources and models for understanding parts of nature. One does not need to endorse to the full Giambattista Vico's maxim that we understand only those things that we can make to admit that he had a point. In fact, we often understand things that we cannot make by using the things we can make as a resource or model for such understanding. More generally, few of us will dispute the more subtle points Norton Wise has made in his work on mediating machines, even if few of us have followed his lead. However, uneasiness crops up when a mere handful of machines are used to construct a historiographic straitjacket in which four centuries of complex and diverse scientific practices are confined. And such discomfort increases when these machines are connected to something that resembles a Zeitgeist. Some of this unease shines through in several commentaries.

There is a legitimate concern that my big picture reduces the four machines to abstract symbols, "emblems," "mere" metaphors, "mental tools," or "embodied intellectual patterns," at the cost of their "technicity" and their role as "actual machines." I admit that this is a danger, inherent in my move from detailed case studies involving actual machines to the broader conceptual realms of the larger scheme. But the way I see it, the possibility of their symbolic or metaphorical role is contingent, or at least partly so, on the role these machines - real machines - played in diverse social and cognitive settings. Seventeenth-century mathematicians and philosophers like Galileo, Hooke, and Huygens studied real clocks and tried to improve their design, just as their nineteenth-century successors, men of science like Joule, Thomson,

Isis, volume 107 , number 4. (C) 2016 by The History of Science Society.

All rights reserved. 0021-1753/2016/0107-0012\$10.00.

800 
Mayer, and Helmholtz, took a strong and genuine interest in real steam engines. Part of my aim is to highlight the role of the material and, more in particular, of machinery in science, not to downplay it.

It is true, however, that even though the machines, as real material artifacts, are at the heart of my big picture, I do tend to extend their emblematic or metaphorical role beyond the cases where this seems warranted by concrete historical examples. I would not be able to arrive at a big picture without doing so. Still, how do I justify such a bold step? I certainly do not hold the view that, taken as emblems or symbols, these machines point to "fundamental and coherent worldviews," "underlying epistemic structures," or "paradigms." Indeed, I have carefully avoided the use of the latter word. Clearly, such a view is untenable nowadays, and I certainly do not want to ignore the fruits of half a century of rich and illuminating microstudies. Like most of us, I see thick description as the best way to make sense of past events. But I also believe that we cannot afford to restrict our work to such studies.

Then how do I see the epistemic structures that I relate to certain machines in certain periods? I have no clear model or theory to offer, but I tend to think of them as a dynamic cluster or network of loosely connected concepts, outlooks, objects, and practices that somehow resonate and, at least temporarily, legitimate and reinforce one another. Although new connections are constantly formed, and existing connections are strengthened, weakened, or even broken, they look metastable during relatively short periods (say, on the order of a decade). Actor-network theory might offer a useful approach to study these clusters, but as yet I do not want to make my scheme dependent on any theory. Let me try to illustrate my point in a general way, using seventeenth-century natural philosophy as an example.

There is no single way to account for the rapid rise of the mechanical philosophy in the second third of the seventeenth century. A fascination for automata and clocks, the increasingly productive role of machines, the problem of longitude, the social rise of engineers, dissatisfaction with substantial forms as an explanatory category, the seventeenth-century revival of classical atomism, the mathematical study of motion, the political and religious crisis of Europe, the commercial revolution, theories of political absolutism, and many other factors somehow contributed to, and were strengthened by, the rise of "the mechanical philosophy." Seventeenth-century authors managed to forge several connections, each highly contingent, between elements of all these different practices and viewpoints, thereby producing a kind of discourse that, for all its variability, flexibility, and contestability, nevertheless has some recognizable features.

The mechanical philosophy certainly meant different things to different actors at the time, and many philosophers did not subscribe to its main tenets. Yet few historians would argue with the claim that in any account of seventeenth-century natural philosophy the mechanical philosophy holds a central position; that in this philosophy matter and motion replaced substantial forms as preferred explanatory principles; that the sobering effects of the mechanical philosophy were welcomed by many in a time of religious strife; that the mathematical study of motion - whether of light rays, terrestrial objects, or heavenly bodies-became a major field of interest among mathematicians at the time; that leading mathematicians at midcentury took an interest in the improvement of clocks; that many natural philosophers compared nature to a clock partly to illustrate the nature of its hidden mechanisms; and that the same model was used to illustrate the relationship between God and his creation and that between the monarch and his subordinates.

In short, clocks, bodies, heavens, nature, motion, mathematics, society, navigation, philosophy, politics, religion, and commerce formed a web of loose (and in some cases tight) connections, and the clock was sufficiently prominent in this network to serve as a pars pro toto. Something similar may be said of the other machines at other times. They all were prominent nodes in complex and dynamic cultural networks. Of course, it is somewhat arbitrary to single 
out machines in preference to other nodes to characterize such a network. They do, however, have certain specific advantages, such as their ability to mediate between society and nature. And, as Harun Küçük aptly puts it, "machines last," and they are mobile. In my scheme the machine, then, has a multiple role. First, it designates or symbolizes this heterogeneous cluster or discourse as a kind of emblem. Second, it functions as an important node in the web of connections that make up the cluster. And third, in its material manifestations it has been a major agent in the creation of part of this discourse by forging such connections. It is the latter two claims that legitimate the former choice. And it is the former choice that should act as an incentive to study the latter processes.

Given my emphasis on changeable connections within a broad cluster of discourses and practices, it does not really matter what the heyday of the steam engine really was (following David Edgerton and Google N-gram I would probably opt for the first half of the twentieth century). As a central node in a web of connections, it flourished from the 1840 s until the end of the nineteenth century. Neither does it matter that the balance has a prehistory that far exceeds that of the other machines (although large, conspicuous weighing houses were built in commercial centers in Northern Europe only in the second half of the seventeenth century). I admit that the balance is probably the weakest link in my scheme. Still, I believe that my approach will work even in this case in view of its prominent position both as a machine and as an element in late eighteenth-century discourse. Apart from the many late eighteenth-century examples pointed out by Norton Wise, Google N-gram suggestively shows a remarkable peak in use of the word "balance" (both the English and the French words) in the second half of the eighteenth century.

Finally, it does not really matter that "information" is not obviously a derivative of computers (although I do believe that Claude Shannon's theory of information owes more to his previous experience with information and communication technologies, such as computers, than to new conceptions of entropy) and that the computer was not the obvious metaphor for several processes in the living cell. During the postwar period there were more than sufficient connections between, for instance, computers, codes, DNA, information, entropy, game theory, and economics to warrant-so I believe - the use of the computer as a proper emblem of what might otherwise be called the "age of information."

Some critics have objected that neither as a metaphor nor as a real object of study did the steam engine play any role in the emergence of Darwinian evolution. They are, of course, perfectly right. Yet I believe that there are many ways to connect the steam engine to Darwin's work in less direct ways. Despite Darwin's rural background, his theory does relate in several ways to modern industrial society. Malthus's theories, one of Darwin's many sources of inspiration, played into Whig economic ideas, and it is not far-fetched to suggest that Adam Smith's emphasis on the economic benefits of the division of labor served as an influence on Darwin's principle of divergence. There may also be a deeper albeit even less direct connection. One of the crucial differences between early modern and late modern views of nature is the predominantly static character of the former and the dynamic character of the latter, captured in such terms as "historicity," "transformation," "irreversibility," "directionality," "progress," and "change." The (irreversible) transformation of energy in the steam engine nicely captures this kind of dynamism (as compared to the cyclical motions of the clock and the equilibrium of the balance, both apt symbols of a static worldview).

In a similar way, Marx's historicist view of society as undergoing a series of fundamental changes or transformations ("The hand-mill gives you society with the feudal lord; the steammill society with the industrial capitalist") connects to the steam engine in several ways. ${ }^{1}$ If

${ }^{1}$ Karl Marx, The Poverty of Philosophy (London: Martin Lawrence, [1937]), p. 92. 
Hobbes's Leviathan relates to the mechanical clock, in which all power is centralized in a single prime mover and the motion it generates is passed on through passive mechanisms, and Montesquieu's L'esprit des lois is the political representation of the weighing scales, in which different powers are carefully balanced, then Marx's Das Kapital naturally connects to the steam engine, in which power is successively transformed from one kind into another. Of course, drawing such connections can easily degenerate into a frivolous game without the scrutiny inherent in a more detailed analysis. As yet, I can only say that I strongly believe that such connections can be shown to be more than superficial analogies.

Given my deliberate choice to focus on machines rather than on several key figures in the history of science, I am not too much concerned about the fact that some of the latter (e.g., Newton) do not exemplify or fully fit the related views of nature. I would even suggest that a more appropriate place for the more innovative minds is at the transition point between two successive epistemic regimes. And this is indeed often the case. Thus, Kepler illustrates the shift from an organic view of nature, with the Sun as a motive soul, to a more mechanical (clockwork) view of the solar system. In a similar vein, Newton embodied the change from a mechanical view of nature to one based on irreducible forces. Likewise, whereas Helmholtz's early work on the conservation of "force" was founded on the supposition of point-like particles exerting attractive and repulsive forces, his later work on the conservation of "energy" built on the British interpretation of energy as the capacity to perform work. Such examples can easily be multiplied.

Still, the question remains: Why these four machines, rather than other possible candidates? As I have tried to show in my opening essay, each of these machines connected in meaningful ways to a fundamental concept that at some point was regarded as an explanatory ultimate, possibly denoting the basic stuff of reality; each of these machines, combined with the related concept, contributed to a fundamental change in conceptions of the nature of life (and mind); and each of these machines came to play a prominent role in philosophical and scientific research. Finally, each of these machines also connected in a natural way to commercial and industrial practices and to contemporary views of society. I know of no other machines that perform as well on all these counts. Indeed, it is their capacity to connect nature to society that I appreciate most in these machines. Even if we reject the outdated view, going back to Emile Durkheim and Marcel Mauss, that the natural order, as perceived by a group of people, is a reflection of the group's social order, this does not exclude the existence of several meaningful relationships between prevalent conceptions of nature and those of society.

Of course, these four machines can only serve as a backbone, to which the rest of the skeleton and all the flesh must be added. My scheme is meant as a starting point rather than as a full picture, and it aims at novices rather than professionals. The picture can be (and needs to be) enriched and nuanced in many ways. One way to do so is by adding several supplementary machines, such as those suggested in some of the commentaries. Another is to point to different uses and interpretations of these machines and to the endurance of the machines and their metaphorical roles. It can and should also be supplemented by other technologies and practices that are not so easily connected to machines. One can think of collecting and classification and, indeed, of statistics. And we also need to correct or question the scheme in those particular cases where it fails or misleads. In fact, one of the advantages of a big picture, even for professionals, is that it allows us to throw our specific findings into relief, if only by contrasting them to such broad outlooks.

Let me end by pointing out what I regard to be the main pedagogical advantages of my big picture. If one starts from the familiar - that is, great scientists and their discoveries - and then adds nuance and historical context, the danger is that the latter wear off and people revert to a historically naive starting point. This danger is smaller if one starts from a basis that is highly 
counterintuitive, in this case machine-based views of nature. This in itself does not necessarily imply ignoring the role of individuals. In a sense it even highlights the originality of the more independent minds that were able to free themselves at least in part from the predominant discourses (although they usually did so by using other time-bound resources). Still, it allows one to put more emphasis on the collective nature of the production of knowledge. Furthermore, it emphasizes the role of material cultures and practices, as well as the multiple connections between time-bound forms of knowledge and society. Finally, I do believe that it is helpful to start from a small number of successive periods, which, in spite of several continuities, show some distinct traits. It helps us to underline the fundamental historicist message, still best expressed in the opening line of L. P. Hartley's novel The Go-Between (1953), that "the past is a foreign country: they do things differently there." 